\title{
The Effect of Static Visual Instruction on Students' Online Learning: A Pilot Study
}

\author{
Pao-Nan Chou and Hsi-Chi Hsiao \\ (The authors contributed equally to this paper) \\ Cheng Shiu University, Kaohsiung, Taiwan (R.O.C.)
}

\author{
pnchou@csu.edu.tw; hchsiao@csu.edu.tw
}

\begin{abstract}
The purpose of the study is to explore the effect of varied static visual instructions on students' online learning. One experimental study was conducted to fulfill the purpose. Sixty undergraduate students majoring in educational-related areas from an American public university participated in the study. The results of the study show that the effect of two static visual instructions (concept map and static image) in facilitating different types of knowledge acquisition in an online environment is the same. During lower-order thinking process, only static visual instruction (static image) is superior to text-based instruction.
\end{abstract}

Keywords: Static visual instruction, Online learning, Experimental study, Educational Technology

\section{Introduction}

Since human beings are visually oriented (Norman, 2004), visual instruction is regard as one of effective learning strategies in different learning environments (Dwyer, 1978, 2007). Reviewing existing literature regarding visual instruction indicates that past studies tended to use multimedia programs, such as Flash software, to design animated visual instruction and ignored the benefits of static visual instruction. A major problem is that the number of studies between static and animated visual instruction is imbalanced.

According to Lin and Dwyer's (2004) study, static and animated visual instruction can with equal effectiveness significantly support student learning. In other words, the effect of static and animated visual instruction on student learning is the same. Therefore, from a cost-effective perspective, whether or not low-cost static visual instruction can replace the role of high-cost animated visual instruction is worthy of exploration.

The current study developed two types of static visual instructions to enhance students' cognitive abilities in an online learning environment. The design rationale of the static visual instructions bases on information process model. Undergraduate students are targeted groups. One random-

Material published as part of this publication, either on-line or in print, is copyrighted by the Informing Science Institute. Permission to make digital or paper copy of part or all of these works for personal or classroom use is granted without fee provided that the copies are not made or distributed for profit or commercial advantage AND that copies 1) bear this notice in full and 2) give the full citation on the first page. It is permissible to abstract these works so long as credit is given. To copy in all other cases or to republish or to post on a server or to redistribute to lists requires specific permission and payment of a fee. Contact Publisher@InformingScience.org to request redistribution permission. ized-based experimental study evaluates the instructional effectiveness of two static visual instructions. Specifically, the purpose of the study is to explore the effect of varied static visual instructions on students' online learning. 


\section{Theoretical Foundation}

According to Atkinson and Shiffrin's (1968) model as illustrated in Figure 1, three important elements in the mind process the information learners receive: (a) sensory memory, (b) short-term memory, and (c) long-term memory. The concepts of the model are:

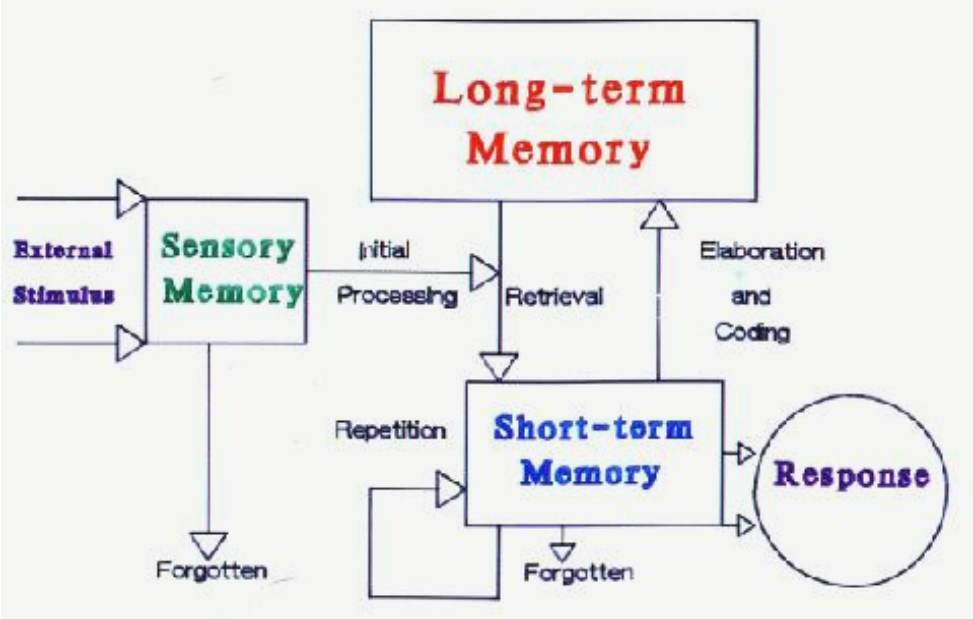

Figure 1. Atkinson and Shiffrin's model of information processing (Source: Huitt, 2003, p3)

1. Sensory memory is the first stage of the model. The senses (e.g. vision, hearing, touch, taste, and smell) in the human body receive the information from the situated environment, and then information transmits to the sensory register in the brain. However, the sensory register only selects the attended information for further consideration. Without this process, the mind would be overwhelmed by too much encountered information.

2. Short-term memory temporarily records the information which passes through the sensory register. The short-term memory has limited size. According to Miller's (1956) study, short-term memory only can hold five to nine chunks. A chunk could refer to digits, words, chess positions, or people's faces. In addition, the information in short-term memory can be retained for only 5 to 20 seconds. If the information can not be transferred to long-term memory in this period of time, the information will be lost. In other words, received information will be forgotten in learners' minds.

3. Long-term memory receives meaningful information from short-term memory. In order to obtain meaningful information, the short-term memory links to prior knowledge already stored in long-term memory. The linking process, encoding information from short-term memory and retrieving information from long-term memory, does not always occur. Compared to short-term memory, long-term memory has limitless size and holds information indefinitely.

In this study, the static visual instruction serves as a powerful learning strategy (Dwyer, 2007) which aims to strength the linking process of information encoding and retrieving between short-term and long-term memory. A research assumption of the study is that varied types of static visual instructions may cause different effects on the linking process between short-term and long-term memory. 


\section{Methods}

\section{Research Participant}

In an experimental study, at least twenty participants in each treatment group are required (Dwyer, 2006). Since this study involves three experimental treatments, the minimum number of participants is sixty. In order to fulfill this requirement, the researcher recruited sixty undergraduate students majoring in educational-related areas from an American public university to participate in this study.

\section{Online Learning Material}

In this study, Dwyer' (1978) reading material regarding human body structure was chosen because (a) "it provides a hierarchy of several types of educational objectives extending from the learning of basic facts to complex problem solving..." (p.44), and (b) its outcome measurements reflect high reliability coefficients. The researcher of the study employed FrontPage software to transform original paper-based document into online hypertext material.

\section{Online Learning Measurement}

Dwyer's three criterion tests are used to measure students' online learning performances. These tests are (Dwyer, 1978, p. 45-47):

(a) Identification test (measuring factual knowledge): This multiple-choice test (20 items) evaluates students' abilities to identify parts or positions of an object. The reliability coefficient (consistency in the measurement) is 0.83 .

(b) Terminology test (measuring conceptual knowledge): This multiple-choice test (20 items) was designed to measure knowledge of specific facts, terms, and definitions. The reliability coefficient is 0.81 .

(c) Comprehension test (measuring rule/principle knowledge): This multiple-choice test (20 items) was designed to measure a type of understanding in which the individual can use the information being received to explain some other phenomenon. The reliability coefficient is 0.77 .

\section{Experimental Treatment}

Each experimental treatment owns its online website, including the same online learning material. A distinct difference among treatments is the provision for visual instruction. The details are:

(a) Treatment 1 (Control group): In this treatment, students only receive the online learning material. No visual instruction is provided (See Figure 2).

(b) Treatment 2 (Static visual instruction 1: Concept map): In this treatment, several concept maps, which summarize the reading contents' main ideas, are inserted into the online learning material (See Figure 3).

(c) Treatment 3 (Static visual instruction 2: Static image): In this treatment, several static images, which relate to reading contents, are inserted into the online learning material (See Figure 4).

\section{Research Hypotheses}

In this study, the independent variable was visual instruction (two types of static visual instruction: concept map and static image); the dependent variables were three criterion tests (identification, terminology, and comprehension test). One research hypothesis is:

No significant differences exist in criterion tests among students receiving different treatments 


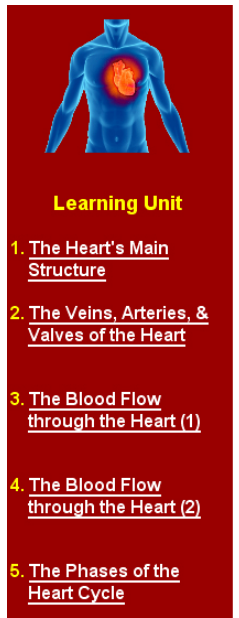

Unit1: The Heart's Main Structure--- [3 pages]

The heart lies toward the front of the body and is in a slanting position between the lungs, immediately below the breastbone. The wide end points toward the right shoulder. The small end of the heart points downward to the front of the chest and toward the left. The lower portion of the heart is called the apex and is the part that you feel beating.

The human heart is really two pumps combined in a single organ which circulates blood to all parts of the body. The heart is divided longitudinally into two halves by the septum. The two halves may be compared to a block of two houses, which are independent of each other but have common wall, the septum, between them.

$-1-$

Previous Next

Figure 2. Sample screenshot from Treatment 1

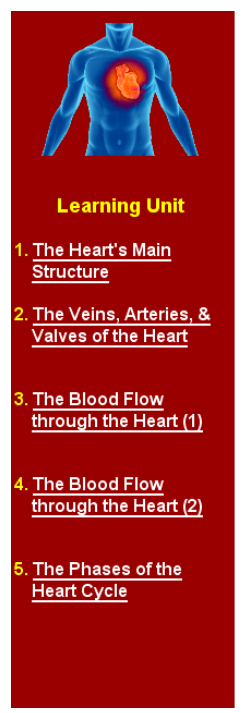

Unit1: The Heart's Main Structure---[3 pages]

The heart lies toward the front of the body and is in a slanting position between the lungs, immediately below the breastbone. The wide end points toward the right shoulder. The small end of the heart points downward to the front of the chest and toward the left. The lower portion of the heart is called the apex and is the part that you feel beating.

The human heart is really two pumps combined in a single organ which circulates blood to all parts of the body. The heart is divided longitudinally into two halves by the septum. The two halves may be compared to a block of two houses, which are independent of each other but have common wall, the septum, between them

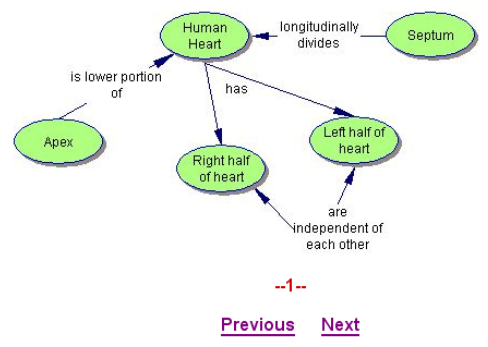

Figure 3. Sample screenshot from Treatment 2

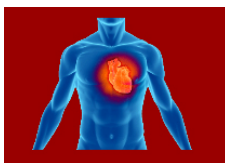

Unit1: The Heart's Main Structure---[3 pages]

Each half of the heart is divided into an upper chamber and a lower chamber. The upper chambers on each side of the septum are called auricles; the lower chambers are called ventricles. Auricles have thin walls and act as receiving rooms for the blood, while the ventricles having thicker walls act as pumps

Learning Unit

1. The Heart's Main Structure

2. The Veins, Arteries, \&

Valves oft

The Blood Flow

through the Heart (1)

4. The Blood Flow

through the Heart (2)

5. The Phases of the

Heart Cycle

moving the blood away from the heart. Although there is no direct communication between the right and left sides, both sides function simultaneously.

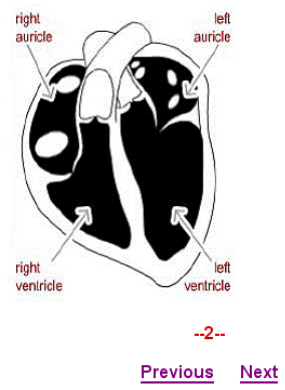

Figure 4. Sample screenshot from Treatment 3 


\section{Research Procedure}

When arriving in a computer lab, participants were randomly assigned into one of the experimental treatments. Subsequently, students opened the Internet browser to view assigned treatment websites. During the one-hour session, students should complete assigned instructions. Immediately upon completion of their respective instructional presentations, students in each treatment received a battery of three tests described earlier. Table 1 shows the distribution of participants across treatment groups.

Table 1. Distribution of Participants in Treatments

\begin{tabular}{ll}
\hline Treatment & Total \\
\hline T1: Control & 20 \\
T2: Concept map & 20 \\
T3: Static image & 20 \\
Total & 60 \\
\hline
\end{tabular}

\section{Threat to Validity}

In the research design, an experimenter must be able to minimize the treats to internal validity (Creswell, 2009; McMillan, 2004). This study adopts a randomization-based experimental design and a one-shot recruitment procedure (i.e. recruiting participants at the computer labs one at a time) which greatly decrease the effect of extraneous factors, such as maturation and diffusion of treatment, affecting internal validity that Campbell and Stanley (1963) addressed.

\section{Data Analysis}

The Statistical Package for the Social Sciences (SPSS) software version 13 was used to complete data analysis. The collected data was analyzed by a statistical technique, One-Way Multivariate Analysis of Variance (MANOVA), whose purpose is to test for treatment group differences when two or more dependent variables are to be considered simultaneously.

\section{Results \& Discussion}

\section{MANOVA Assumption Check}

Before conducting MANOVA analysis, three statistical procedures must be checked: (a) correlation between dependent variables, (b) normality of dependent variables, and (c) homogeneity of variance among dependent variables (Morgan \& Griego, 1998; Tabachnick \& Fidell, 2007). First of all, Pearson's correlation technique analyzed three dependent variables (i.e. three criterion tests). As Table 2 shows, each dependent variable highly correlates. All correlation coefficients are higher than $0.7(\mathrm{p}<0.01)$, indicating a strong relationship exists among each criterion test.

Table 2. Pearson's Correlation among Dependent Variables

\begin{tabular}{llll}
\hline Criterion Test & Identification & Terminology & Comprehension \\
Identification & 1 & $0.80^{*}$ & $0.78^{*}$ \\
Terminology & $0.80^{*}$ & 1 & $0.84^{*}$ \\
Comprehension & $0.78^{*}$ & $0.84^{*}$ & 1 \\
$*$ Correlation significant at the 0.01 level &
\end{tabular}

Second, descriptive statistics tested the normality of dependent variables. The result in Table 3 indicates that skewness is $0.10(<1)$ with kurtosis of $1.08(<10)$ in the identification test; skewness 
is $0.26(<1)$ with kurtosis of $0.82(<10)$ in the terminology test; skewness is $0.41(<1)$ with kurtosis of $1.06(<10)$ in the comprehension test. According to the standards of Kline (1998) and Huck (2008), these values are acceptable.

Table 3. Skewness and Kurtosis of Criterion Test

\begin{tabular}{lll}
\hline Criterion Test & Skewness & Kurtosis \\
Identification & 0.10 & 1.08 \\
Terminology & 0.26 & 0.82 \\
Comprehension & 0.41 & 1.06 \\
\hline
\end{tabular}

The final step is to verify the homogeneity of variance among criterion tests. Levene's test of equality of error variances was analyzed with the results appearing in Table 4 . The results show that significance values in each test are higher than 0.05 . In other words, the error variance of the dependent variable is equal across groups.

Table 4. Levene's Test of Equality of Error Variances

\begin{tabular}{lllll}
\hline Criterion Test & F & df1 & df2 & Significance \\
Identification & 1.41 & 2 & 57 & 0.25 \\
Terminology & 0.99 & 2 & 57 & 0.38 \\
Comprehension & 1.63 & 2 & 57 & 0.21 \\
\hline
\end{tabular}

Based on the previous statistical assumptions' check, one-way MANOVA analysis is justified for analyzing collected data in this study.

\section{Results of MANOVA}

Table 5 reports the results of MANOVA.

Table 5. Results of MANOVA

\begin{tabular}{|c|c|c|c|c|c|c|}
\hline \multicolumn{2}{|c|}{ Source } & SS & DF & MS & $\mathrm{F}$ & $\mathrm{P}$ \\
\hline \multirow[t]{3}{*}{1} & Between Groups & 358.43 & 2 & 179.22 & 7.44 & $0.00 *$ \\
\hline & Within Groups & 1373.75 & 57 & 24.10 & & \\
\hline & Total & 1732.18 & 59 & & & \\
\hline \multirow[t]{3}{*}{2} & Between Groups & 127.03 & 2 & 63.52 & 2.90 & 0.63 \\
\hline & Within Groups & 1247.70 & 57 & 21.89 & & \\
\hline & Total & 1374.73 & 59 & & & \\
\hline \multirow[t]{3}{*}{3} & Between Groups & 76.30 & 2 & 38.15 & 1.68 & 0.20 \\
\hline & Within Groups & 1294.55 & 57 & 22.71 & & \\
\hline & Total & 1370.85 & 59 & & & \\
\hline
\end{tabular}

1: Identification; 2: Terminology; 3: Comprehension ${ }^{*}$ Significant value $<0.05$

From the results shown in Table 5, the effect of instructional treatment was found in one criterion test (Identification test: $\mathrm{F}=7.44, \mathrm{p}=0.00<0.05$ ). No significant differences exist in the terminology and comprehension tests. Therefore, a follow-up comparison procedure, Tukey HDS, was performed to analyze the identification test. The results appear in Table 6. 
Table 6. Tukey HDS Analysis of MANOVA

\begin{tabular}{lll}
\hline In identification test & Mean Difference & $\mathrm{P}$ \\
\hline Treatment $1 \& 2$ & -2.40 & 0.28 \\
Treatment $1 \& 3$ & -5.95 & $0.00^{*}$ \\
Treatment $2 \& 3$ & -3.55 & 0.07 \\
\hline
\end{tabular}

*Significant value $<0.05$

From the results shown in Table 6 , in the identification test, a statistically significant difference exists between Treatment 1 and Treatment $3(p=0.00<0.05)$. No significant differences were found between Treatment 1 and Treatment 2, and Treatment 2 and Treatment 3 . However, since the $p$ value between Treatment 2 and Treatment 3 is close to 0.05 , whether or not increasing sample size will yield a significant difference is worthy of further exploration.

\section{Test of Research Hypothesis}

In summary, the results of MANOVA and Tukey HDS analysis show that significant differences were found between two treatment groups in the identification test. The effect of instructional treatment indeed exists in this study. Therefore, the research hypothesis was rejected at 0.05 confidence level. Specifically, in the identification test, students in Treatment 3 (static image) performed better than Treatment 1 (control group).

\section{Conclusions}

From the results of MANOVA, students in Treatment 3 performed better than Treatment 1 in the identification test. In other words, the static visual instruction (static image) can significantly support students' online learning at the aspect of factual knowledge (lower-order thinking). However, no significant difference was found between Treatment 2 and Treatment 3 in all criterion tests. Therefore, from a statistical perspective, two static visual instructions own equal effectiveness on student online learning from lower-order (factual knowledge) to higher-order cognitive thinking process (principle knowledge).

In this study, the effect of two static visual instructions (concept map and static image) in facilitating different types of knowledge acquisition in an online environment is the same. During lower-order thinking process, only static visual instruction (static image) is superior to text-based instruction. Therefore, based on information processing model (Atkinson \& Shiffrin, 1968), varied types of static visual instructions in the current study cause the same effect on the linking process between short-term and long-term memory.

According to Campbell and Stanley (1963), external validity relates to the generalizability of experimental results. Since the characteristics of participants (undergraduate students), research settings (computer lab), experimental treatments (two static visual instruction designed for this research), and measures (criterion tests), limitations to generalizability of research findings in this study may exist.

Even though some potential limitations are present for this study, the findings may be generalized to the following situations:

1. Individuals: Since the students involved in this study are from normal undergraduate classes, a conclusion may be that the findings are appropriate to similar types of students who take online courses.

2. Instructional materials: Although this study is conducted in the computer lab, the learning materials at treatment websites are similar to those appearing in online courses. The conclusion may be that the findings are appropriate to similar types of instructional materials in online courses. 
Based on this study's discussion and conclusions discussed earlier, a number of recommendations for future research are proposed:

1. Individual differences: Individual differences may influence the results of the study. Future studies can examine the effect of individual differences (locus of control, intelligence, and field dependent/field independent) on students' online learning.

2. Sample size: This study only recruited 60 participants. Future studies can replicate this study by increasing the sample size.

3. Reading time: Students in this study completed the assigned instructional treatments in different reading speeds. Future studies can record participants' reading time and examine the effect on students' online learning.

4. Different learning materials: This study only tested the instructional effectiveness of two static visuals by using science-oriented human heart. Future studies can integrate two static visuals into contents of different subjects (economics or English literature) in the hypertext environments.

\section{References}

Atkinson, R. C., \& Shiffrin, R. M. (1968). Human memory: A proposed system and its control processes. In K. W. Spence \& J. T. Spence (Eds.), The psychology of learning and motivation (Volume 2) (pp. 89-193). New York: Academic Press.

Campbell, D. T., \& Stanley, J. C. (1963). Experimental and quasi-experimental designs for research. Chicago: Rand McNally.

Creswell, J.W. (2009). Research design: Qualitative, quantitative, and mixed methods approaches ( ${ }^{\text {rd }}$ ed.). Thousand Oaks, CA: SAGE Publications.

Dwyer, F. M. (1978). Strategies for improving visual learning. State College, PA: Learning Services.

Dwyer, F. M. (2006). Handbook of an experimental study. State College, PA: The Pennsylvania State University.

Dwyer, F. M. (2007). The program of systematic evaluation (PSE): Evaluating the effects of multimedia instruction 1965-2007. Educational Technology, XLVII(5), 41-45.

Huck, S. W. (2008). Reading statistics and research (5th ed.). New York: Addison Wesley Longman.

Huitt, W. (2003). The information processing approach to cognition. Educational Psychology Interactive. Valdosta, GA: Valdosta State University. Retrieved Feb 15, 2007 from, http://chiron.valdosta.edu/whuitt/col/cogsys/infoproc.html

Kline, P. (1998). Principles and practice of structural equation modeling. NY: Guiford Press.

Lin, C., \& Dwyer, F. (2004). Effect of varied animated enhancement strategies in facilitating achievement of different educational objectives. International Journal of Instructional Media, 31(2), 185-198.

McMillan, J. H. (2004). Educational research: Fundamentals for the consumer ( $4^{\text {th }}$ ed.). Boston: Person Education.

Miller, G.A. (1956). The magic number seven plus or minus two: Some limits on our capacity for processing information. Psychological Review, 63(2), 81-97.

Morgan, G. A., \& Griego, O. V. (1998). Easy use and interpretation of SPSS for Windows: Answering research questions with statistics. Mahwah, NJ: Lawrence Erlbaum Associates.

Norman, D. A. (2004). Emotional design: Why we love (or hate) everyday things. NY: Basic Books.

Tabachnick, B. G., \& Fidell, L. S. (2007). Using multivariate statistics ( $5^{\text {th }}$ ed.). Boston, MA: Allyn \& Bacon. 


\section{Biography}

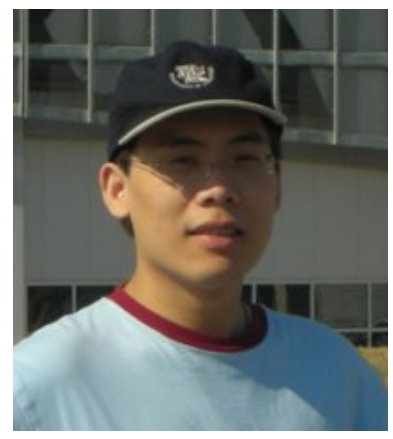

Pao-Nan Chou is a post-doctoral fellow in the Research Lab of Engineering \& Technology Education at Cheng Shiu University. He received his B.S. in Electronic Engineering \& Computing Education and M.S. in Workforce Education \& Development from National Taipei University of Technology, Taiwan. He also received his M.Ed. and Ph.D. in Instructional Systems from The Pennsylvanian State University, USA. His research interests include e-learning and engineering education.

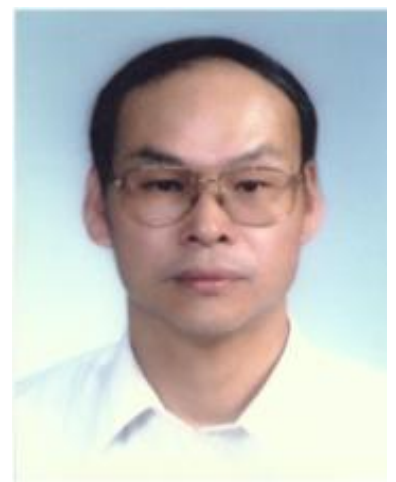

His-Chi Hsiao is the director in the Research Lab of Engineering \& Technology Education and chair professor in the Graduate Institute of Business Administration at Cheng Shiu University. He received his B.S. in Industrial Technology \& Education from National Taiwan Normal University, Taiwan. He also received his M.Ed. in Industrial Education from The University of Wisconsin, USA and Ph.D. in Curriculum \& Instruction from The Indiana State University, USA. His research interests include human resource development and management, and engineering education. 